\title{
Tamanho da raiz, pêlos radiculares e infecção por micorrizas: um reexame da hipótese de Baylis com árvores tropicais
}

\author{
T. V. St. John (*)
}

\section{Resumo}

Uma série de 89 espécies da floresta brasileira, nas quais as características da raiz e a condição da micortiza V-A eram conhecidas, foram usadas para testar um aspecto da hipótese de raiz magnolióide de Baylis. Um teste estatístico não-paramétrico mostrou uma significativa associação entre as características da raiz magnolióíde e a infecção V.A.

\section{INTRODUÇÃO}

Baylis (1975) sugere que as raízes primitivas de angiosperma, exemplificadas pelás da ordem Magnoliales, são particularmente dependentes do fungo micorriza vesicular-arbuscular para absorção de minerais. Ele definiu a raiz magnolióide, que não precisa ocorrer somente nas Magnoliales, como a rudemente ramificada com as últimas radículas geraimente com mais de $0,5 \mathrm{~mm}$ de diâmetro. Estas raizes geralmente não têm pêlos radiculares, e muitas destas espécies de plantas reagem à infecção por micorrizas mesmo em solos relativamente férteis.

Baylis contrastou o tipo graminóide com raíze magnolióides. As raízes graminóides podem ter ramificações com menos de $0,1 \mathrm{~mm}$ de diâmetro e freqüentemente têm uma densa cobertura de longos pêlos radiculares. Espécies de plantas com tais raizes geralmente reagem à infecção por miccrriza somente nos solos mais deficientes em fósforo. A maioria das espécies é do tipo intermediário, com o tamanho das úitimas radículas e a cobertura de pêlos radiculares entre estes extremos.

Baylis organizou 20 espécies de plantas, a maioria com raizes do tipo intermediáric, em uma série refletindo suas dependências da infecção por micorrizas. A tabela mostrou uma pequena tendência no sentido da diminuição do diâmetro da raiz e uma forte tendência no sentido de uma contínua cobertura de longos pêlos radiculares com decrescente micotrofia.

Baylis observou que espécies tropicais estavam grandemente ausentes de sua investigação de tipos de raízes e micotrofia. Um exame de micorriza vesicular-arbuscular em uma floresta tropical amazônica tem proporcionado uma oportunidade para parcialmente reconstruir o estudo de Baylis. Dados sobre reação à infecção e fertilização com fósforo estãc ausentes uma vez que todas as coietas apresentadas aqui foram de árvores maduras da floresta. Contudo, dados sobre diâmetro da raíz e freqüência e comprimento dos pêlos radiculares permitem que as espécies sejam organizadas em uma sequêencia usando uma aproximação ligeiramente diferente: de magnolióide a graminóide, colocando-se aqueles com pêlos radiculares em um extremo da série. Uma medida relativa do estado de micorriza no campo foi então usada para testar a hipótese específica de que raízes magnolióides são mais prováveis de suportar infecção por micorrizas do que graminóides

\section{MÉTodos}

COLETA DOS ESPÉCIMES - A maioria das espécies foi coletada de um lote de um hectare de floresta tropical primária de planície em um oxissol muito pesado nas proximidades de Manaus, Brasil. O local foi levantado por Prance et. al. (1976) e todas as árvores com mais de $15 \mathrm{~cm}$ DBH foram identificadas e rotuladas. Umas poucas espécies foram coletadas em um spodossol (podzol tropical) extremamente pobre em nutrientes, também perto de Manaus. Estas incluem várias ervas e arbustos além de árvores. Elas foram identificadas por A. Anderson do instituto Nacional de Pesquisas da Amazônia. Em cada caso, uma amostra da raiz foi coletada por escavação

(") - Natural Resources Ecology Laboratory, Colorado State University, Fort Collins, CO 80523, U.S.A. 
para fora da base de uma planta identificada; até raízes de identidade confirmada apresentarem radículas de última ordem, não $ı$ enho sas. Usualmente cerca de $50 \mathrm{ml}$ (arrañjadas ao acaso) destas raízes foram levadas ao laboratório para preparaçăo.

DETERMINAÇÃO DA CONDIÇÃO DE MICORRIZA - Amostras das raízes foram limpas e coradas pelo método de Phillips \& Hayman (1970) e examinadas com um microscópio de dissecação. Subamostras imaginadas provavelmente como sendo infectadas foram montadas em glicerina em lâminas e examinadas sob um microscópio composto. O padrão geral para julgamento de infecção foi a presença de "hifas" internas. Vesiculas não foram comuns e arbúsculos quase nunca evidentes em plantas nativas coletadas no campo. Eventuais amostras de raizes foram tão densas que uma clarificação satisfatória fora aparentemente impossivel com estas técnicas; em tais casos o julgamento foi baseado na "hifa" externa, da característica tipo endogonáceo.

Plantas classificadas como "não micorrizal" foram aquelas que nunca suportavam infecção. Aquelas classificadas "ligeiramente infectada" tiveram eventuais pontos de infecção isolados. Infecção "moderada" significou que muitas partes da amostra apresentaram infecção e "forte" significou que a maior parte das raizes na amostra estava infectada com "hifa" ou outras estruturas V-A. Um método mais quantitativo foi rejeitado face ao grande número de amostras a serem examinadas e ao fato de que cada amostra representava somente uma pequena, não ao acaso amostra de cada sistema de raíz da planta; uma maior precisão seria de pouco uso sem uma medida de variabilidade. A ampla categoria subjetiva foi imaginada como mais provavelmente por ser consistente entre repetições, uma discussão que foi amplamente apoiada para espécies amostradas repetidamente.

Espécies classificadas como "não-micorrizal" foram coletadas em, pelo menos duas ocasiões, a não ser que eles fossem de espécie muito rarã. As mais comuns foram coletadas várias vezes, geralmente de diferentes árvores, sem considerar-se a condição micorrizal.
Amostras de todas as espécies infectadas ou não, foram montadas em lâminas em glicerina para determinação das características da raiz. Em cada caso uma amostra das raizes mais finas na amostra foram montadas.

MEDIDAS DE RAÍZES E PÊLOS RADICUI.ARES - A presença de pêlos radiculares em qualquer parte das amostras foi registrada durante o exame com o microscópio de dissecação.

$\mathrm{O}$ diâmetro da raiz foi medido na radícula mais fina presente na amostra e a média destas registradas para a espécie. Em vários casos, as radículas de última ordem foram distendidas; neste caso, as ramificaçōes distendidas foram medidas mesmo que ligeiramente maiores que a penúltima ordem. Uma vez que as lâminas estiveram preparadas para a determinação da condição micorrizal, as amostras foram um pouco achatadas. Uin fator de correção do diâmetro padrão de 0.7 toi calculado das amostras para as quais raizes comprimidas e não comprimidas estiveram disponiveis. A aplicação uniforme deste fator em espécimes variavelmente achatados provavelmente introduziu um pequeno erro na largura relativa das várias espécies. Certamente isto não altera substancialmente suas posições na seqüência contudo, e é uma melhor estima. tiva do diâmetro original do que as medidas não modificadas.

O comprimento dos pêlos radiculares em umas poucas espécies foram estimadas de observações feitas durante o exame inicial se nenhum pêlo radicular estivesse incluído nos montes permanentes.

Enquanto três espécies ectomicorrizas, uma ericaceous e várias orchidaceous foram examinadas, estas foram excluídas das análises nos locais que estes outros tipos de micorriza não puderam ser relacionadas do mesmo modo com a morfologia da raíz.

ANÁLISE DOS DADOS - As espécies foram organizadas em uma série de magnolióides a graminóide com raízes sem pêlos postas em ordem de diâmetro decrescente. Todas as raízes com pêlos radiculares vinham após estes e foram distribuídos primeiro por frequeência (rara, inconstante ou constante), e dentro da freqüência por comprimento do pêlo radicular. Para cada espécie foi designado um grau, com 
as raízes graminóides recebendo os graus mais baixos. Aos graus foram então fixadas categorias de infestação micorrizal e a análise de variância do método de Kruskal-Wallis por grau (Siegel, 1956) aplicada para determinar se os graus foram distribuidos equitativamente entre as categorias de micorrizas.

A Taxonomia foi baseada em Cronquist (1968) para plantas com flores e Lawrence (1951) para samambaias.

\section{Resultados}

RAÍzes MAGNOLIÓIDES - Os seis membros das Magnoliales examinados no trabalho (Aniba duckei, Licaria aurea, L. sp., e Nectandra rubra das Lauraceae, Unonopsis stipitata das Annonaceae e Siparuna sp. das Monimiaceae) tiveram diâmetro de raíz entre 0,165 e
$0,853 \mathrm{~mm}$, com um valor médio de $0,429 \mathrm{~mm}$ (tabela 1). Isto foi um tanto menor que a amplitude de Baylis de 0,35 a $1,5 \mathrm{~mm}$. A diferença pode ser devida à pequena populaçăo de tamanhos de raízes nas Magnoliales tropicais, podendo estar relacionado ao fator de correção usado neste estudo (ver métodos) ou pode ser erro de amostragem. Em qualquer dos casos, estes resultados podem ser considerados como concordantes, de uma maneira geral, com os resultados de Baylis. Das 23 ordens representadas neste estudo, somente duas tiveram média de tamanho de raíz maiores. Ambas são pobremente representadas e uma não é uma ordem de plantas com fiores e não possuem raízes verdadeiras. Nenhuma dentre as Magnoliales teve pêlos radiculares e todas estavam forte ou moderadamente infestadas com fungo micorrizal VA.

TABELA 1 - Características da raiz e condição micorrizal de 89 plantas tropicais americanas de 23 ordens

\begin{tabular}{|c|c|c|c|c|c|c|c|c|}
\hline \multirow{2}{*}{ Ordem } & \multirow{2}{*}{$\begin{array}{c}\text { Espécie } \\
\left(n .^{\circ}\right)\end{array}$} & \multirow{2}{*}{$\begin{array}{c}\text { Diâmetro } \\
\text { da raiz * } \\
(\mathrm{mm})\end{array}$} & \multirow{2}{*}{$\begin{array}{l}\text { Pêlos } \\
\text { radicula- } \\
\text { res }\end{array}$} & \multirow{2}{*}{$\begin{array}{l}\text { Comprimento } \\
\text { médio dos } \\
\text { pêlos radi- } \\
\text { culares } \\
(\mathrm{mm})\end{array}$} & \multirow{2}{*}{ Nāo } & \multicolumn{3}{|c|}{ Categoria micorriza: } \\
\hline & & & & & & Pouco & moderado & forte \\
\hline Magnoliales & 6 & $429 \pm 252$ & 0 & - & 0 & 0 & 3 & 3 \\
\hline Urticales & 7 & $323 \pm 285$ & 2 & 108 & 3 & 1 & 1 & 2 \\
\hline Teales & 3 & $134 \pm 18$ & 2 & 97 & 1 & 0 & 1 & 1 \\
\hline Malvales & 5 & $248 \pm 103$ & 1 & 100 & 0 & 1 & 4 & 0 \\
\hline Lecithidales & 9 & $267 \pm 108$ & 0 & - & 3 & 6 & 0 & 0 \\
\hline Violales & 2 & $194 \pm 59$ & 1 & 123 & 1 & 0 & 0 & 1 \\
\hline Ebenales & 7 & $318 \pm 302$ & 3 & 132 & 3 & 1 & 3 & 0 \\
\hline Rosales & 13 & $326 \pm 239$ & 0 & - & 3 & 1 & 4 & 5 \\
\hline Myrtales & 5 & $171 \pm 117$ & 0 & - & 2 & 1 & 0 & 2 \\
\hline Santalales & 2 & $384 \pm 121$ & 1 & 400 & 1 & 0 & 1 & 0 \\
\hline Celastrales & 3 & $301 \pm 288$ & 1 & 131 & 2 & 1 & 0 & 0 \\
\hline Rhamnales & 1 & 161 & 0 & - & 1 & 0 & 0 & 0 \\
\hline Sapindales & 7 & $244 \pm 42$ & 2 & 108 & 2 & 1 & 1 & 3 \\
\hline Linales & 2 & $252 \pm 46$ & 0 & - & 0 & 1 & 1 & 0 \\
\hline Polygalales & 4 & $199 \pm 26$ & 0 & - & 0 & 0 & 4 & 0 \\
\hline Gentianales & 1 & 610 & 0 & - & 0 & 1 & 0 & 0 \\
\hline Rubiales & 2 & $117 \pm 13$ & 1 & 368 & 0 & 1 & 1 & 0 \\
\hline Asterales & 1 & 432 & 0 & - & 0 & 0 & 0 & 1 \\
\hline Arecales & 2 & $497 \pm 269$ & 0 & - & 1 & 0 & 1 & 0 \\
\hline Cyperales & 3 & $80 \pm 40$ & 1 & $?$ & 1 & 0 & 2 & 0 \\
\hline Polemoniales & 1 & 553 & 0 & - & 0 & 1 & 0 & 0 \\
\hline Eriocaulales & 1 & 172 & 0 & - & 1 & 0 & 0 & 0 \\
\hline \multicolumn{9}{|l|}{ Pteridophyta: } \\
\hline Eufilicales & 2 & 660 & 0 & - & 0 & 0 & 1 & 1 \\
\hline
\end{tabular}

(-) Média \pm D.P.

(*) Número de espécies com pêlos radiculares.

(…*) Nâo = não micorrizal; pouco = ligeiramente infectado; mod. = moderadamente infectado; forte $=$ fortemente infectado. 
Da amplitude de valores mostrada pelas magnoliales neste $\in$ studo, parece que o diâmetro de $0,3 \mathrm{~mm}$ foi uma razoável, embora um tanto arbitrária linha divisória entre magnclıoides e tipos de raízes intermediárias nesta série. Vinte e nove espécies sem pêlos radiculares foram maiores que $0,3 \mathrm{~mm}$ e somente um membro das Magnoliales (Licaria sp.) foi menor.

RAÍZES INTERMEDIÁRIAS E GRAMINÓIDES Nenhuma das espécies estudadas foi verdadeiramente graminóide no sentido de possuirem uma constante cobertura densa de pêlos radiculares com 1-2 mm. Somente 15 espécies tiveram pêlos radiculares em todas as raizes, destas, quatro foram classificadas como raras, cinco inconstantes e seis constantes. Elas variaram em comprimento de 0,044 até $0,400 \mathrm{~mm}$, com uma espécie indeterminada, face à ausência de observações adequadas ou material para medição.

Quarenta e cinco espécies sem pêlos radiculares caíram abaixo do tamanho limite arbitrário de $0,3 \mathrm{~mm}$ para raízes magnolióides. Estas foram tão finas como seriam aquelas com pêlos radiculares pela classificação original.

Associação de infestação V-A e tipo de raiz: $\mathrm{O} \mathrm{H}$ estatístico produzido pela análise de variância método de Kruskal-Wallis por graus foi 12,52. Com 3 graus de liberdade, este valor é estatisticamente significativo $(p<0,01)$. A preponderância de altos graus na categoria "fortemente micorrizal" e baixos graus na categoria "não-micorrizal" (tabela 2) mostra claramente onde as diferenças estão:

TABELA 2 - Graus médios" em 4 categorias de in. fecção micorrizal

\begin{tabular}{|c|c|c|c|c|c|}
\hline & \multicolumn{3}{|c|}{ Categoria micorrizal ${ }^{* *}$} & \multirow[b]{2}{*}{ Forte } & \multirow[b]{2}{*}{$\begin{array}{c}\text { Combi- } \\
\text { nada }\end{array}$} \\
\hline & Não & Pouco & Mod & & \\
\hline $\begin{array}{l}\text { Número de } \\
\text { espécies } \\
\text { Grau médio }\end{array}$ & 24 & 17 & 29 & 19 & 89 \\
\hline na categoria & 31.8 & 47.0 & 45.1 & 59.7 & 45.9 \\
\hline
\end{tabular}

raízes magnolióides tendem a ser fortemente infestadas e, graminóides (ou raízes intermediárias tipo graminoide) tendem a ser não infestadas.

\section{DISCUSSÃo}

A presente investigação, embora organizada em uma base ligeiramente diferente da de Baylis, sustenta certas controvérsias daquele estudo. O exame de seis representantes tro. picais americanos das Magnoliales confirmam amplamente sua descrição do sistema de raíz magnolióide generalizado. Estes sistemas de raizes foram encontrados como pertencentes à categoria "fortemente micorrizal" com desporporcionada freqüência e, a maioria dos sistemas de raíz tipo graminóide pertencendo desproporcionadamente à categoria "não micorrizal", desta maneira, apoiando a hipótese específica que raízes magnolióides são mais prováveis de serem infectadas.

Sistemas de raíz magnolióide foram notadas como muito comuns na floresta tropical, em contraste com raízes verdadeiramente graminóides, que estiveram aparentemente ausentes. Raízes relativamente finas ou aquelas com algum desenvolvimento de pêlos radiculares foram consideravelmente menos comuns que as raízes magnolióides, mas ocorreram. Uma boa quantidade dos tipos intermediários, assim como também numerosas raízes tipo graminóide e umas poucas raízes magnolióides foram totalmente não micorrizal ou só ligeiramente infectadas. O significado disto será discutido em uma publicação subseqüente.

\section{Agradecimentos}

Dr. J. Gerdemann sugeriu a aplicação destes dados perguntando se minhas desco. bertas confirmavam a hipótese da Baylis: sua sugestão é por isto agradecida.

O trabalho de campo para este estudo foi apoiado por uma subvenção dada ao Dr. Paulo de Tarso Alvim pelo Conselho Nacional de Desenvolvimento Científico e Tecnológico (CNPq). A preparação do manuscrito foi financiada pela Subvenção DEB78-11201 da National Science Foundation (Fundação Nacional de Ciência). 


\section{SUMMARY}

A series of 89 Brazilian forest species for which root characteristics and V-A mycorrhizal condition were known was used to test an aspect of Baylis's magnolioid root hypothesis. A non-parametric statistical test showed a significant association between magnolioid root characteristics and V-A infection.

\section{BIBLIOGRAFIA}

BAYLIS, G.T.S.

1975 - The magnolioid mycorrhiza and mycotrophy in root systems derived from it. In: F.E. Sanders, B. Mosse, and P. B. Tinker, editors. Endomycorrhizas. London; Academic Press. 626 p.

CRONQUIST, A.

1968 - The evolution and classification of flowering plants. London, Nelson, 396 p.
LAWRENCE, G.H.M

1951 - Taxonomy of vascular plants. New York The Mac-Millan Company. 823 p.

PhIllips, J.M. \& HaYman, D.S.

1970 - Improved procedures for clearing roots and staining parasitic and vesicular-arbuscular mycorrhizal fungi for rapid assessement of infection. Trans. Br. Mycol. Soc., 35(1) : 158-161.

Prance, G.T.; Rodrigues, W.A. \& Silva, M.F. da 1976 - Inventário florestal de um hectare de mata de terra firme $\mathrm{km} 30$ de Estrada Manaus-Itacoatiara. Acta Amazonica, 6(1):9-35.

Siegel, S.

1956 - Non-parametric statistics for the behavioral sciences. New York, McGraw-Hill Book Company. $312 p$.

(Aceito para publicação em 15/08/79) 